\title{
Interaction of hydrogen with actinide dioxide (111) surfaces
}

Cite as: J. Chem. Phys. 150, 134701 (2019); https://doi.org/10.1063/1.5087577

Submitted: 02 January 2019. Accepted: 03 March 2019 . Published Online: 01 April 2019

James T. Pegg (D), Ashley E. Shields (D), Mark T. Storr, David O. Scanlon (D), and Nora H. de Leeuw (D)

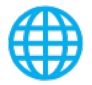

\section{ARTICLES YOU MAY BE INTERESTED IN}

A consistent and accurate ab initio parametrization of density functional dispersion correction (DFT-D) for the 94 elements H-Pu

The Journal of Chemical Physics 132, 154104 (2010); https://doi.org/10.1063/1.3382344

Hybrid functionals based on a screened Coulomb potential

The Journal of Chemical Physics 118, 8207 (2003); https://doi.org/10.1063/1.1564060

Investigation of near-surface defects of nanodiamonds by high-frequency EPR and DFT calculation

The Journal of Chemical Physics 150, 134702 (2019); https://doi.org/10.1063/1.5085351

\section{Lock-in Amplifiers up to $600 \mathrm{MHz}$}
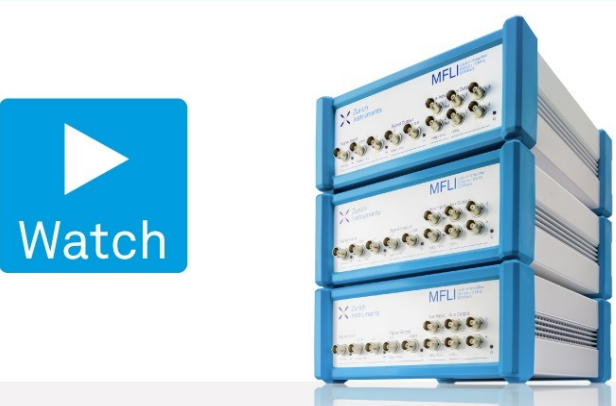


\title{
Interaction of hydrogen with actinide dioxide (111) surfaces
}

\author{
Cite as: J. Chem. Phys. 150, 134701 (2019); doi: 10.1063/1.5087577 \\ Submitted: 2 January 2019 Accepted: 3 March 2019 • Published Online: 1 April 2019
}

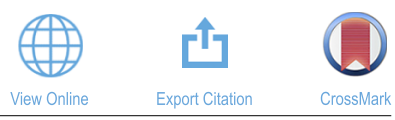

James T. Pegg, ${ }^{1,2, a)}$ (D) Ashley E. Shields, ${ }^{3}$ (D) Mark T. Storr, ${ }^{2}$ David O. Scanlon, ${ }^{1,4,5}$ (D) and Nora H. de Leeuw

\begin{abstract}
AFFILIATIONS
${ }^{1}$ Department of Chemistry, University College London, 20 Gordon Street, London WC1H OAJ, United Kingdom

${ }^{2}$ Atomic Weapons Establishment (AWE) Plc, Aldermaston, Reading RG7 4PR, United Kingdom

${ }^{3}$ Oak Ridge National Laboratory, One Bethel Valley Road, Oak Ridge, Tennessee 37831, USA

4Diamond Light Source Ltd., Diamond House, Harwell Science and Innovation Campus, Didcot, Oxfordshire OX11 ODE, United Kingdom

${ }^{5}$ Thomas Young Centre, University College London, Gower Street, London WC1E 6BT, United Kingdom

${ }^{6}$ School of Chemistry, Cardiff University, Main Building, Park Place, Cardiff CFID 3AT, United Kingdom
\end{abstract}

a) Author to whom correspondence should be addressed: pegg.james.t@gmail.com

\begin{abstract}
The interaction of atomic and molecular hydrogen with actinide dioxide $\left(\mathrm{AnO}_{2}, \mathrm{An}=\mathrm{U}, \mathrm{Np}, \mathrm{Pu}\right)(111)$ surfaces has been investigated by $\mathrm{DFT}+\mathrm{U}$, where noncollinear $3 \mathrm{k}$ antiferromagnetic behaviour and spin-orbit interactions are considered. The adsorption of atomic hydrogen forms a hydroxide group, coupled to the reduction of an actinide ion. The energy of atomic hydrogen adsorption on the $\mathrm{UO}_{2}(0.82 \mathrm{eV}), \mathrm{NpO}_{2}$ $(-0.10 \mathrm{eV})$, and $\mathrm{PuO}_{2}(-1.25 \mathrm{eV})$ surfaces has been calculated. The dissociation of molecular hydrogen is not observed, shown to be due to kinetic rather than thermodynamic factors. As a barrier to the formation of a second hydroxyl group, an unusual charge distribution has been shown. This could be a limitation of a (1-1) unit cell method or an artefact of the systems. The recombination of hydrogen ions on the AnO ${ }_{2}$ (111) surfaces is favoured over hydroxide formation.
\end{abstract}

\section{INTRODUCTION}

The corrosion of actinide materials concerns nuclear industries, where the radiolysis of organic compounds and other sources generate hydrogen. ${ }^{7-6}$ This is known to catalyse the corrosion of the actinide metals. ${ }^{7,8}$ Incidents involving corrosion have resulted in thermal excursions, expansion of solids, formation of incondensable gases, and containment failure. ${ }^{9}$ The interaction of hydrogen with nuclear materials must be understood (imperative to the design of long-term storage facilities), ${ }^{10}$ where the corrosion and oxidation of the actinide metals are often treated as equivalent topics. $^{11}$

The actinide metals are highly reactive elements. The corrosion chemistry is controlled by the initial actinide dioxide $\left(\mathrm{AnO}_{2}\right)$ layer, formed by the unavoidable oxidation of the metal surface. ${ }^{7,9,11-17}$ As an active template for the equilibration of the hydrogen-oxygen system, knowledge of the electronic structure of the $\mathrm{AnO}_{2}$ is critical to the understanding of corrosion mechanisms. ${ }^{5,18-20} \mathrm{~A}$ number of investigations have shown the $\mathrm{AnO}_{2}$ (111) surface to be the most stable. The interpretation of the corrosion mechanism is highly complex, inferred from studies with hydrogen, oxygen, and water. ${ }^{5,9}$ These involve the complex interplay of thermodynamic, kinetic, and catalytic factors. ${ }^{11}$ A diffusion-controlled mechanism for oxygen migration across the oxide layer to the metaloxide interface fails to account for hydrogen-catalysed oxidation and pyrophoric behaviour. $8,11,13,21,22$ The influence of hydrogen on $\mathrm{AnO}_{2}$ corrosion chemistry is unclear. Mechanisms for watercatalysed corrosion often incorporate the diffusion of hydrogen $\left(\mathrm{H}\right.$ or $\left.\mathrm{H}^{+}\right)$or hydrogen-containing species $\left(\mathrm{H}_{2} \mathrm{O}\right.$ or $\left.\mathrm{OH}\right)$ across the oxide surface layer to the metal-oxide interface. ${ }^{23}$ In addition, the mechanism is thought to include the formation of hyperoxides $\left(\mathrm{AnO}_{2+\mathrm{x}}\right)$ which increases the oxygen concentration gradient, thereby facilitating the migration of $\mathrm{O}^{2-}$ ions to the metal-oxide interface.

The interaction of hydrogen within the crystal structure and water adsorption has been investigated in earlier studies. ${ }^{18-20,23-29}$ 
The interplay of binding and formation energies has been shown to impact the thermodynamic stability of oxy-hydroxyl defects, where hydrogen stabilises isolated Willis clusters and greatly impacts the stability of oxygen clusters to form irreversible traps. ${ }^{27,30}$ The occupation of octahedral interstitial sites (early $\mathrm{AnO}_{2}$ ) or the formation hydroxyl groups (late $\mathrm{AnO}_{2}$ ) by hydrogen has been shown to be controlled by the actinide element. ${ }^{24}$ The formation energies of light impurity atoms $(\mathrm{H}, \mathrm{He}, \mathrm{Li}, \mathrm{Be}, \mathrm{B}, \mathrm{C}, \mathrm{N}, \mathrm{O}, \mathrm{F}$, and $\mathrm{Ne}$ ) are influenced by $\mathrm{AnO}_{2} \cdot{ }^{24}$ The relative stability of the hydride ion compared to the hydroxyl group in $\mathrm{UO}_{2}$ has been shown, where the uranium $5 f$ electrons can form chemical bonds. The hydroxyl group is relatively stable in $\mathrm{PuO}_{2}$ by contrast, where the plutonium $5 \mathrm{f}$ electrons are more localised. ${ }^{23}$ The formation of hydroxyl groups on isostructural cerium dioxide $\left(\mathrm{CeO}_{2}\right)$ has also been found; however, cerium is a lanthanide element characterised by more simplistic behaviour. $^{31}$

The interaction of hydrogen with $\mathrm{AnO}_{2}$ surfaces is experimentally difficult to study. ${ }^{12}$ The rate of corrosion is influenced by the extent of radiation damage, environmental conditions, and surface energetics. A limited number of experimental $\mathrm{AnO}_{2}$

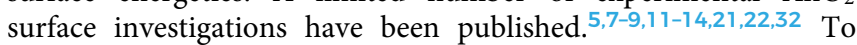
compliment experimental investigations of $\mathrm{AnO}_{2}$ surfaces, computational methods offer another method of study. ${ }^{23-29}$ Although theoretical investigations are nontrivial, ${ }^{15,16,33-35}$ the actinides are highly correlated f-electron systems for which conventional methods often fail. To calculate highly correlated systems, a number of methods have been developed. These include the selfinteraction correction (SIC) method, ${ }^{36}$ modified density functional theory $(\mathrm{DFT}+\mathrm{U}),{ }^{37-41}$ hybrid density functionals, ${ }^{42-44}$ and dynamic mean field theory (DMFT). ${ }^{45}$ Of these methods, $\mathrm{DFT}+\mathrm{U}$ is widely employed and offers a tractable means of study.

A fluorite-type structural motif is adopted by the $\mathrm{AnO}_{2}$ under normal environmental conditions. At low temperature, the $\mathrm{AnO}_{2}$ $(\mathrm{An}=\mathrm{U}, \mathrm{Np}$, and $\mathrm{Pu})$ show noncollinear $3 \mathrm{k}$ antiferromagnetic (AFM) behaviour. ${ }^{46-51}$ The transverse $3 \mathrm{k}$ AFM state of $\mathrm{UO}_{2}$ and $\mathrm{NpO}_{2}$ results in $\mathrm{Pa} \overline{3}$ (No. 205) crystal symmetry, ${ }^{35}$ whereas the longitudinal 3k AFM state of $\mathrm{PuO}_{2}$ results in $\mathrm{Fm} \overline{3} m$ (No. 225) crystal symmetry. ${ }^{34,52}$ In each instance, the external cubic symmetry is retained. In contrast with collinear $1 \mathrm{k}$ AFM states, a reduction of cubic crystal symmetry has been found. ${ }^{34}$ The importance of spin-orbit interactions (SOI) in the actinide elements has been highlighted; ${ }^{53}$ however, the impact of relativistic contributions is often ignored for computational simplicity. ${ }^{54-56}$ Noncollinear magnetic behaviour is also infrequently considered. ${ }^{34,52}$ The corrosion chemistry of the $\mathrm{AnO}_{2}$ (111) surface is controlled by the electronic structure. ${ }^{27}$ To mirror the corrosion chemistry of $\mathrm{AnO}_{2}$, the electronic structure must be correctly calculated. ${ }^{33}$

The importance of noncollinear magnetic behaviour and spinorbit interactions (SOI) on the electronic structure has been highlighted by a number of investigations. ${ }^{6,33-35,52,53,55}$ In this paper, the interaction of hydrogen with the $\mathrm{AnO}_{2}(\mathrm{An}=\mathrm{U}, \mathrm{Np}$, and $\mathrm{Pu})$ (111) surface has been investigated by DFT+U. These calculations incorporate noncollinear 3k AFM behaviour and SOI influences. As the surface offers a nonuniform interface, inequivalent adsorption sites have been investigated. The electronic structure is compared against the clean surface, and this can be found in the supplementary material. 33

\section{COMPUTATIONAL METHODOLOGY}

\section{A. Calculation details}

A noncollinear relativisitic study has been completed with the Vienna $A b$ initio Simulation Package (VASP) code. ${ }^{36,45,57}$ A planewave basis set, relativistic effective core potentials (ECPs), and the frozen-core projector-augmented wave (PAW) method have been used. ${ }^{43,58}$ The cut-off energy of the planewave basis set is $500 \mathrm{eV}$. The hydrogen $\left(1 \mathrm{~s}^{1}\right)$, oxygen $\left(2 \mathrm{~s}^{2}, 2 \mathrm{p}^{4}\right)$, uranium $\left(6 \mathrm{~s}^{2}, 7 \mathrm{~s}^{2}\right.$, $\left.6 \mathrm{p}^{6}, 6 \mathrm{~d}^{2} 5 \mathrm{f}^{2}\right)$, neptunium $\left(6 \mathrm{~s}^{2}, 7 \mathrm{~s}^{2}, 6 \mathrm{p}^{6}, 6 \mathrm{~d}^{2} 5 \mathrm{f}^{3}\right)$, and plutonium $\left(6 s^{2}, 7 s^{2}, 6 p^{6}, 6 d^{2} 5 f^{4}\right)$ valence electrons are implicitly considered. The integration over the Brillouin zone with the Gaussian method has been completed. ${ }^{59}$ Noncollinear magnetic wave-vectors and SOI are considered. The on-site Coulomb repulsion of the An $5 \mathrm{f}$ electrons is treated by the Liechtenstein et al. formulism, in which the Coulomb (U) and exchange (J) modifiers are treated as independent variables. ${ }^{37-41}$ The exchange-correlation energy is evaluated by the revised Perdew-Burke-Ernzerhof for solid (PBEsol) functional, the improved performance of which

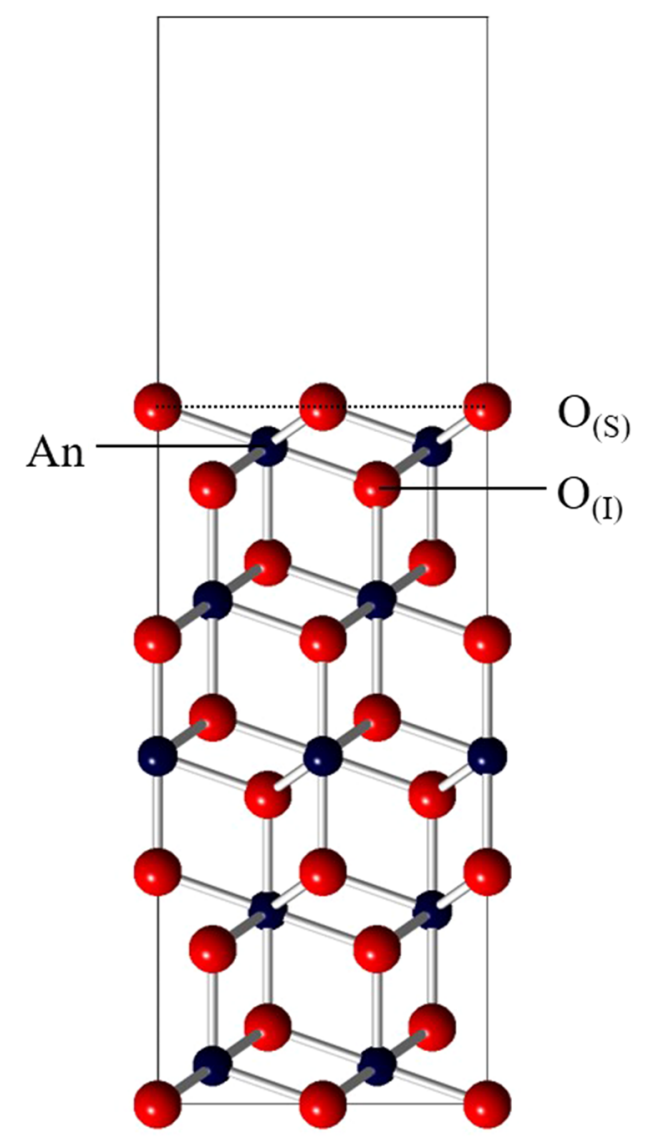

FIG. 1. The low-index $\mathrm{AnO}_{2}$ (111) surface. The $\mathrm{An}^{4+}$ (blue) and $\mathrm{O}^{2-}$ (red) ions are indicated. The superior (primary layer, S) and inferior (tertiary layer, I) oxygen ions are labeled. The surface plane bisects the $\mathrm{Os}^{2-}$ ions as illustrated by the dashed black line. The surface model is comprised of 15 (5 O-An-O units) monolayers. 
has been tested against other functionals. ${ }^{52,60}$ In this study, all ions are fully relaxed with the conjugant gradient algorithm as implemented by VASP. The iteration threshold for electronic and ionic convergence is $1 \times 10^{-5} \mathrm{eV}$ and $1 \times 10^{-2} \mathrm{eV} \cdot \AA^{-1}$, respectively.

A transverse $3 \mathrm{k}$ AFM state for $\mathrm{UO}_{2}(\mathrm{U}=3.35 \mathrm{eV}, \mathrm{J}=0.00 \mathrm{eV})$ and $\mathrm{NpO}_{2}(\mathrm{U}=4.25 \mathrm{eV}, \mathrm{J}=0.00 \mathrm{eV}$ ) with $\mathrm{Pa} \overline{3}$ (No. 205, 0.014$0.016 \AA$ distortion) crystal symmetry is used, ${ }^{35}$ whereas for $\mathrm{PuO}_{2}$, a longitudinal $3 \mathrm{k}$ AFM $(\mathrm{U}=6.00 \mathrm{eV}, \mathrm{J}=0.00 \mathrm{eV})$ model with $\mathrm{Fm} \overline{3} m$ (No. 225) crystal symmetry is used, ${ }^{34}$ the implementation of which has already been documented. The surface is constructed from the ionically relaxed bulk structure with the METADISE code (Fig. 1). ${ }^{16,61}$ The surface is formed of 15 monolayers (5 O-An-O units) with a vacuum gap of $20 \AA$; this is sufficient to isolate the surface from its periodic image. The convergence of the $\Gamma$-centred k-point grid $(5 \cdot 5 \cdot 1)$ (recommended for hexagonal constructs) has been checked. $., 33,62$

\section{B. Inequivalent positions}

The adsorption of atomic $\mathrm{H}$ and molecular $\mathrm{H}_{2}$ on the $\mathrm{AnO}_{2}$ (111) surfaces is considered for multiple inequivalent lattice sites, where the influence of magnetic inequivalence is assumed to be negligible (Fig. 2). The inequivalent oxygen sites are differentiated by their position relative to the plane of the surface: superior $(\mathrm{s})$ or inferior (I). The plane of the surface is defined as that which extends across the $\mathrm{O}_{\mathrm{S}}{ }^{2-}$ ions.

For molecular $\mathrm{H}_{2}$, the orientation of the molecule is considered. In this study, molecular $\mathrm{H}_{2}$ is either placed orthogonal (v) to the plane of the surface or parallel (n) along the direction of a bond. In each configuration, hydrogen is situated at a minimum of $1 \AA$ above the plane of the surface. The implementation of a dipolar correction is not needed in our treatment; hydrogen is adsorbed on both sides of the model with inverse crystal symmetry. The seven inequivalent sites of the $\mathrm{AnO}_{2}$ (111) surface include; three atomic [An, $\mathrm{O}_{(\mathrm{S})}$, $\mathrm{O}_{(\mathrm{I})}$ ] positions, three $\left[\mathrm{An}-\mathrm{O}_{(\mathrm{S})}, \mathrm{An}-\mathrm{O}_{(\mathrm{I})}, \mathrm{O}_{(\mathrm{S})}-\mathrm{O}_{(\mathrm{I})}\right]$ bridging sites, and one interstitial (I) site. The ionic coordinates, magnetic vectors, and dimensions of the unit cell can be found in the supplementary material. 6,33

\section{Hydrogen adsorption}

The hydrogen adsorption energy $\left(\mathrm{E}_{\mathrm{ads}}\right)$ is calculated from the fully ionically relaxed cells. The total energy of the slab with the adsorbate $\left(\mathrm{E}_{\text {slab+absorbate }}\right)$, the energy of the adsorbate $\left(\mathrm{E}_{\mathrm{absorb} a t e}\right)$, and the clean (adsorbate-free) slab energy $\left(\mathrm{E}_{\text {slab }}\right)$ are indicated

$$
\mathrm{E}_{\mathrm{ads}}=0.5\left(\mathrm{E}_{\text {slab }+ \text { absorbate }}-\left(\mathrm{E}_{\text {slab }}+\mathrm{E}_{\text {absorbate }}\right)\right) .
$$

The energy of the adsorbate $\left(\mathrm{E}_{\text {absorbate }}\right)$ is derived from the isolated $\mathrm{H}_{2}$ molecule in a $10 \AA^{3}$ cubic cell. Integration of the Brillouin zone is completed with a $1 \cdot 1 \cdot 1 \Gamma$-centred k-point mesh. The PBEsol calculations result in a $\mathrm{H}-\mathrm{H}$ bond length $\left(\mathrm{r}_{\mathrm{H}-\mathrm{H}}\right)$ of $0.758 \AA$, in good agreement with the experimental value of $0.740 \AA .{ }^{63}$ In terms of the adsorption energy, $\mathrm{E}_{\mathrm{ads}}$, negative values correspond to an energetically favourable exothermic process, while positive values correspond to an endothermic one. The adsorption energy $\left(E_{a d s}\right)$ is calculated from the full ionic relaxation. The dissociation energy of molecular $\mathrm{H}_{2}\left(\mathrm{E}_{\mathrm{ds}}=4.478 \mathrm{eV}\right)$ has been measured by fluorescence-excitation spectroscopy. ${ }^{64,65}$ A difference of $0.152 \mathrm{eV}$ is introduced by PBEsol $\left(\mathrm{E}_{\mathrm{ds}}=4.630 \mathrm{eV}\right)$, which can impact the calculation of adsorption energetics. To measure physisorption energies for $\mathrm{H}(\sim 0.010-0.200 \mathrm{eV})$, the PBEsol error is considerable; however, to measure chemisorption energies for $\mathrm{H}$ $(\sim 1-2 \mathrm{eV})$, the PBEsol error is relatively insignificant. All models consider SOI.

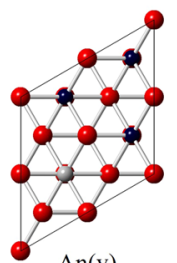

$\operatorname{An}(\mathrm{v})$

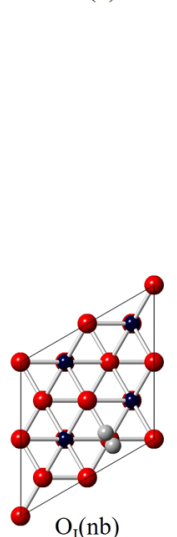

$\mathrm{O}_{\mathrm{I}}(\mathrm{nb})$
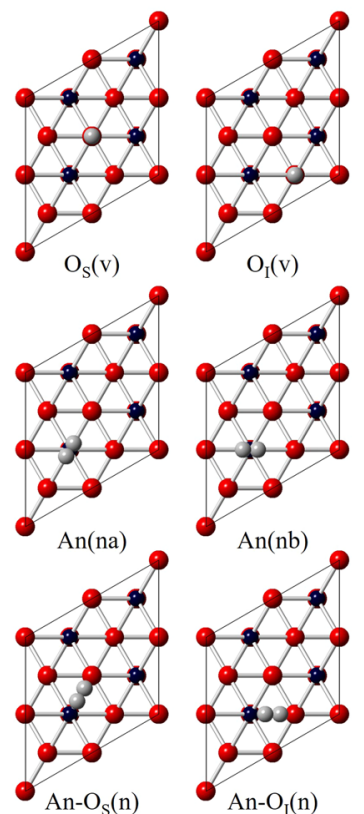

$\mathrm{An}-\mathrm{O}_{\mathrm{S}}(\mathrm{n})$

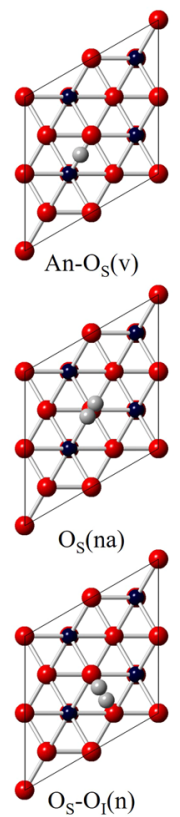

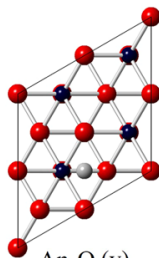

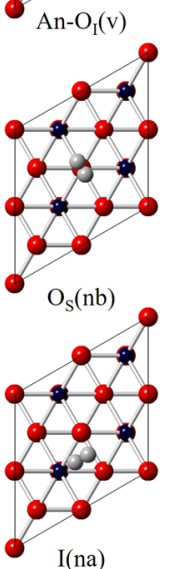

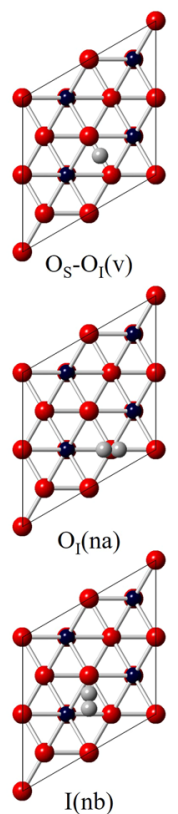

$\mathrm{I}(\mathrm{nb})$
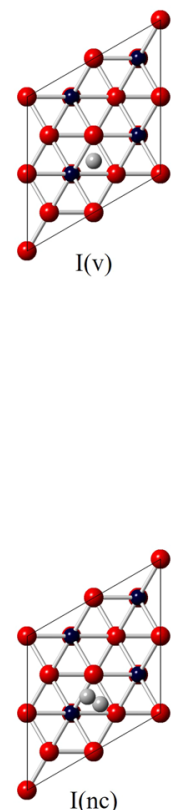

FIG. 2. The initial inequivalent config urations for the adsorption of atomic and molecular hydrogen on the $\mathrm{AnO}_{2}$ (111) surface. The $\mathrm{An}^{4+}$ (blue) and $\mathrm{O}^{2-}$ (red) ions are indicated. The individual hydrogen positions are shown in grey. The minimum distance of the hydrogen atoms above the plane of the surface is $1 \AA$. The hydrogen molecule is considered with either orthogonal (v) or parallel $(n)$ orientations relative to the surface plane. 


\section{RESULTS AND DISCUSSION}

\section{A. Uranium dioxide}

Two interaction sites for atomic $\mathrm{H}-\mathrm{UO}_{2}$ (111) adsorption have been identified, both of which are endothermic in nature (Fig. 3). In hydrogenation and oxidation corrosion mechanisms, endothermic adsorption has been shown to be an important component. ${ }^{66}$ The energetic ordering can be inferred from the position of the $\mathrm{H}$ s-band in the density of states (DoS), where lower energy states indicate a more stable configuration. In the high-energy $\mathrm{aH}_{(111)}$ configuration, atomic $\mathrm{H}$ is located above an $\mathrm{U}$ ion and remains relatively isolated. The electronic structure is relatively unaffected, and no obvious hybrid $\mathrm{OH}$ sp-states are formed. The diagnosis is confirmed by the minimum U-H (2.001 $\AA$ ) and O-H $(2.589 \AA)$ bond distance, which indicates that only weak interactions can occur. A weak hydride $\left(\mathrm{H}^{-}\right)$ion from the Bader charge $(-0.35 \mathrm{eV})$ has been indicated. In the low-energy $\mathrm{bH}_{(111)}$ configuration, the interaction results in an unusual endothermic chemisorption mechanism. The formation of an $\mathrm{OH}$ ion is confirmed by the $\mathrm{O}-\mathrm{H}$ bond distance $(0.975 \AA)$, hybrid $\mathrm{OH}$ sp-states $(-9 \mathrm{eV}$ to $-8 \mathrm{eV})$, and Bader charge analysis $(\mathrm{H}=0.61 \mathrm{eV})$. The corresponding reduction of an $\mathrm{U}$ ion is confirmed by the Bader charge reduction of the $\mathrm{U}(\mathrm{d})$ ion $(2.55 \mathrm{eV}$ to $2.19 \mathrm{eV})$ and the formation of the $\mathrm{U}$ f-defect in the bandgap. As the $\mathrm{U}(\mathrm{a}-\mathrm{c})$ ions are closer in proximity to the $\mathrm{H}$ ion, the reduction of the outermost $U$ (d) ion is unusual in terms of electrostatics.
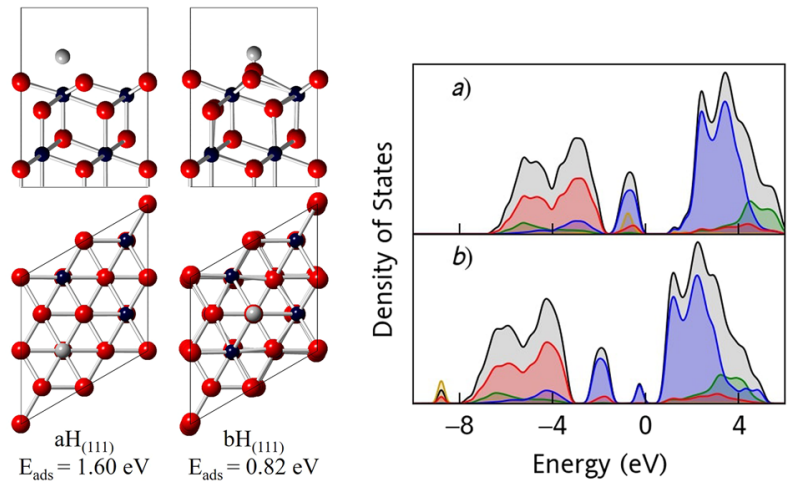

FIG. 3. The adsorption sites of atomic $\mathrm{H}$ on the $\mathrm{UO}_{2}$ (111) surface. The $\mathrm{U}^{4+}$ (blue) $\mathrm{O}^{2-}(\mathrm{red})$, and $\mathrm{H}$ (grey) ions are indicated. The energy of adsorption $\left(\mathrm{E}_{\text {ads }}\right)$ is also shown. The density of states of the $\mathrm{a}-\mathrm{bH}_{(111)}$ configurations for the $\mathrm{UO}_{2}$ (111) surface has been calculated. The total density of states (black), $\mathrm{U} \mathrm{f}-$ (blue), $\mathrm{U} \mathrm{d}$ (green), $\mathrm{O}$ p- (red), and $\mathrm{H} \mathrm{s}$ - (yellow) bands are coloured. Note: the hydrogen $s$-band has been magnified by a factor of 40 for clarity.

In earlier investigations with stoichiometric $\mathrm{UO}_{2}$ models, hydride $\left(\mathrm{H}^{-}\right)$ions are formed within interstitial sites. ${ }^{26}$ The formation of the $\mathrm{OH}$ group was $0.27 \mathrm{eV}$ higher in energy. It was also found that the compensating cation was distinct from the octahedral cage. The result indicates that reduction of the outermost cation is an
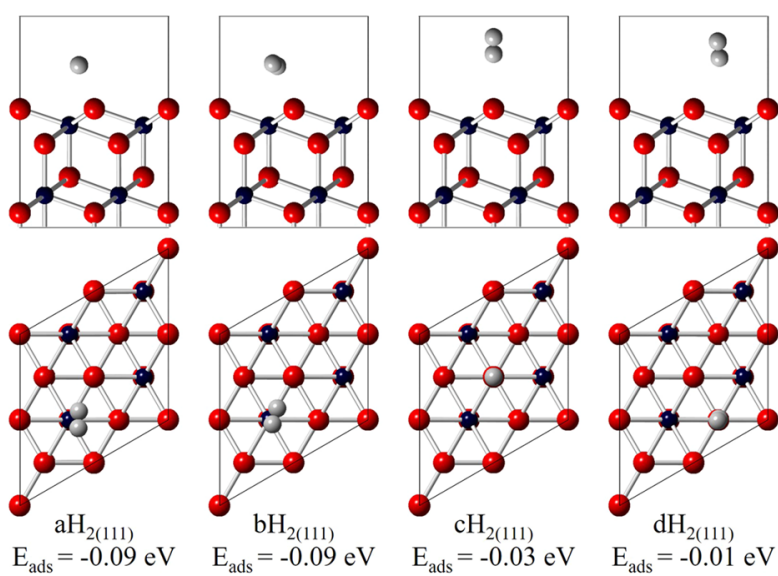

$\mathrm{E}_{\mathrm{ads}}=-0.01 \mathrm{eV}$

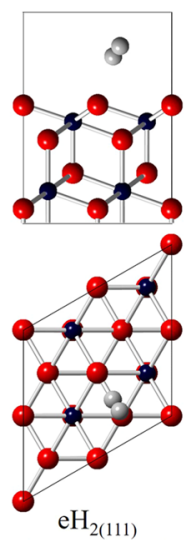

$\mathrm{E}_{\mathrm{ads}}=-0.03 \mathrm{eV}$

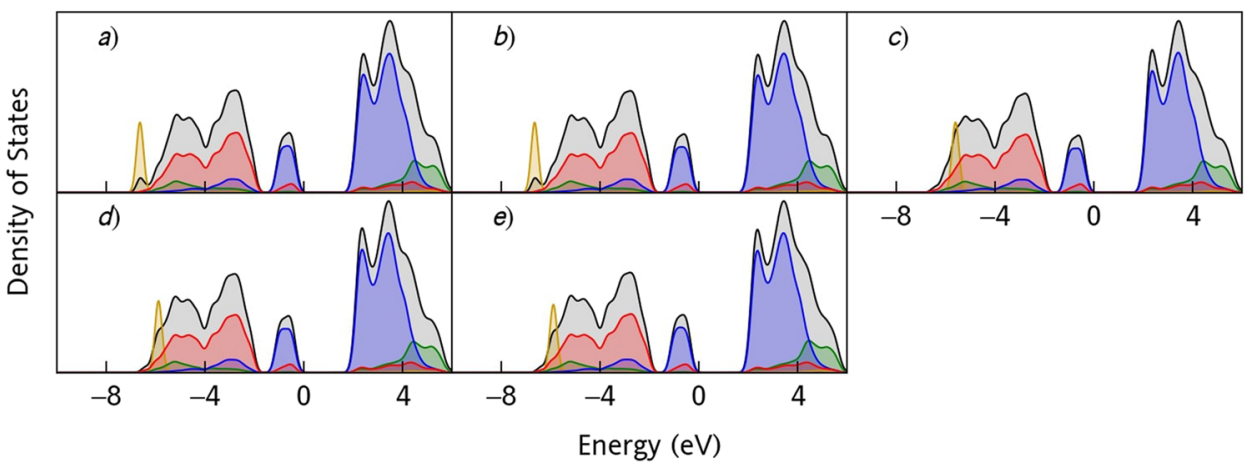

FIG. 4. The adsorption sites of molecular $\mathrm{H}_{2}$ on the $\mathrm{UO}_{2}$ (111) surface. The $\mathrm{U}^{4+}$ (blue), $\mathrm{O}^{2-}$ (red), and $\mathrm{H}$ (grey) ions are indicated. The energy of adsorption $\left(E_{a d s}\right)$ is also shown. The density of states of the a-e $\mathrm{H}_{2(111)}$ configurations for the $\mathrm{UO}_{2}$ (111) surface has been calculated. The total density of states (black), U f- (blue), Ud- (green), Op- (red), and $\mathrm{H}$ $s$ - (yellow) bands are coloured. Note that the hydrogen s-band has been magnified by a factor of 10 for clarity. 
artefact of the system, where further experimental and computational investigation is needed. In contrast with hydrogen-surface interactions, the formation of an $\mathrm{OH}(0.975 \AA)$ group is $(0.78 \mathrm{eV})$ lower in energy; here, the surface offers an oxygen-rich region which can bind local high concentrations of hydrogen. ${ }^{27}$

The adsorption of molecular $\mathrm{H}_{2}$ on the $\mathrm{UO}_{2}$ (111) surface is non-dissociative, where five distinct $\left[\mathrm{a}-\mathrm{eH}_{2(111)}\right]$ configurations have been found (Fig. 4). In each instance, molecular $\mathrm{H}_{2}$ is adsorbed in the $-0.01 \mathrm{eV}$ to $-0.10 \mathrm{eV}$ energy range. In the low-energy a-b $\mathrm{H}_{2(111)}$ configurations, molecular $\mathrm{H}_{2}$ is located proximal to the $\mathrm{U}$ ion. In the $\mathrm{aH}_{2(111)}$ configuration, the $\mathrm{H}$ ions occupy chemically equivalent positions and are slightly off-centre from the $U$ ion, whereas in the $\mathrm{bH}_{2(111)}$ configuration, the $\mathrm{H}$ ions are directed towards a nearby $\mathrm{O}_{(\mathrm{S})}$ ion. The nearby electrostatic attraction to an $\mathrm{O}_{(\mathrm{S})}$ ion is evident in each instance. If dissociation of the molecular $\mathrm{H}_{2}$ were to occur, two mechanisms are possible: (1) the $\mathrm{H}$ ions separate uniformly along adjacent $\mathrm{U}-\mathrm{O}(\mathrm{s})$ bonds forming chemically equivalent $\mathrm{OH}$ ions, (2) the $\mathrm{H}-\mathrm{H}$ bond is elongated along a single $\mathrm{U}-\mathrm{O}(\mathrm{s})$ bond forming an $\mathrm{UH}$ and $\mathrm{OH}$ pair. Although climbing nudged elastic band (cNEB) calculations are computationally unfeasible (due to the expense of noncollinear relativistic investigations), future investigations should consider these pathways.

In the $\mathrm{cH}_{2(111)}$ configuration, molecular $\mathrm{H}_{2}$ is located directly above an $\mathrm{O}_{(\mathrm{S})}$ ion, offering another possibility for molecular $\mathrm{H}_{2}$ dissociation, whereby one $\mathrm{H}$ ion initially forms an $\mathrm{OH}$ group. The dissociative mechanism could then proceed to the formation of a second $\mathrm{OH}$ group involving the remaining $\mathrm{H}$ ion. In the high-energy $\mathrm{dH}_{2(111)}$ configuration, molecular $\mathrm{H}_{2}$ is located above an $\mathrm{O}_{(\mathrm{I})}$ ion orthogonal to the plane of the surface. Given the relatively high energetics of this configuration, it is unlikely to play any role in the dissociation of the $\mathrm{H}_{2}$ molecule. In the $\mathrm{eH}_{2(111)}$ configuration, molecular $\mathrm{H}_{2}$ is proximal to the $\mathrm{O}_{(\mathrm{I})}$ ion and directed towards the neighbouring $\mathrm{O}_{(\mathrm{S})}$ ion, which is suggestive of the electrostatic attraction of hydrogen to the $\mathrm{O}_{(\mathrm{S})}$ ion as a prelude to dissociation. The electronic structure for molecular $\mathrm{H}_{2}$ adsorption on the $\mathrm{UO}_{2}$ (111) surface, as indicated by the DoS, has been calculated for the a- $\mathrm{eH}_{2(111)}$ configurations (Fig. 4). The absence of defect states or hybrid $\mathrm{H} \mathrm{s}$ - and $\mathrm{O}$ p-states, in the a- $\mathrm{eH}_{(111)}$ configurations, indicates that molecular $\mathrm{H}_{2}$ is physisorbed. The magnitude of the electrostatic interaction is indicated by the position of the $\mathrm{H}$ s-band.

The dissociation of molecular $\mathrm{H}_{2}$ is not observed on the $\mathrm{UO}_{2}$ (111) surface, although there is clear evidence of atomic $\mathrm{H}$ chemisorption. The adsorption energies, DoS, and optimized geometries indicate that molecular $\mathrm{H}_{2}$ is physisorbed onto the (111) surface, which is likely to be due to a large energetic barrier for the dissociation pathways relative to the energetically favourable $(-0.10 \mathrm{eV}$ to $-0.01 \mathrm{eV})$ physisorption based on van der Waals interactions. A series of cNEB calculation could confirm this diagnosis. As of the unusual charge distribution in the atomic $\mathrm{aH}_{(111)}$ configuration, the absence of dissociation may be a limitation of a $(1 \cdot 1)$ unit cell model. The charge distribution is unusual in terms of electrostatics, where the outermost surface An ion is reduced. In contrast, a (2.2) unit cell would offer the option of distributing the charge imparted by the adsorption of a $\mathrm{H}$ ion over a larger surface area. One notes that the distribution of charge and the separation of hydrogen ions over a greater surface would introduce a significant energetic barrier for dissociation.
As a limitation of noncollinear relativistic models, a full systematic study of a $(2 \cdot 2)$ unit cell is computationally unfeasible at this time.

\section{B. Neptunium dioxide}

An exothermic adsorption energy of $-0.10 \mathrm{eV}$ is calculated for the $\mathrm{aH}_{(111)}$ configuration, formed by the interaction of atomic $\mathrm{H}$ on the $\mathrm{NpO}_{2}$ (111) surface (Fig. 5). This differs from the endothermic adsorption energy of $0.82 \mathrm{eV}$ for the $\mathrm{UO}_{2} \mathrm{bH}_{(111)}$ configuration, although the configurations are structurally nearly identical. Atomic $\mathrm{H}$ is adsorbed directly above an $\mathrm{O}_{(\mathrm{S})}$ ion, and the $\mathrm{OH}$ group is characterised by a bond length of $0.975 \AA$. In conjunction with the formation of an $\mathrm{OH}$ group, the Bader charge distribution confirms a $\mathrm{H}$ protonic state (Table $\mathrm{A} 2$ ). In contrast to atomic $\mathrm{H}$ adsorption on $\mathrm{UO}_{2}$ (111) and $\mathrm{PuO}_{2}$ (111) surfaces, no other stable configurations have been identified.

The formation of an $\mathrm{OH}$ group is confirmed by the hybridisation of the $\mathrm{H} \mathrm{s}$ - and $\mathrm{O}$ p-states at $-8 \mathrm{eV}$. The bandgap Np f-defect and the Bader charge analysis show the reduction of the $\mathrm{Np}(\mathrm{d})$ ion. The defect state reduces the bandgap of $\mathrm{NpO}_{2}$ to $0.16 \mathrm{eV}$, and Mott-Hubbard characteristics are identified. In comparison with experimental data, the bandgap $(0.40-3.10 \mathrm{eV})$ of $\mathrm{NpO}_{2}$ differs considerably. ${ }^{67-69}$ As hydrogen is notoriously difficult to remove from experimental studies, its impact on X-ray adsorption and epitaxial thin-film measurements is shown. ${ }^{67-69}$

The interaction of molecular $\mathrm{H}_{2}$ on the $\mathrm{NpO}_{2}$ (111) surface generates five distinct a- $\mathrm{eH}_{2(111)}$ configurations (Fig. 6). The dissociation of molecular $\mathrm{H}_{2}$ on the $\mathrm{NpO}_{2}$ (111) surface (as with $\mathrm{UO}_{2}$ and $\mathrm{PuO}_{2}$ ) is not observed. The electronic structure indicates that molecular $\mathrm{H}_{2}$ is physisorbed in each instance. In the low-energy $\mathrm{aH}_{2(111)}$ configuration, molecular $\mathrm{H}_{2}\left(\mathrm{E}_{\mathrm{ads}}=-0.10 \mathrm{eV}\right)$ is located
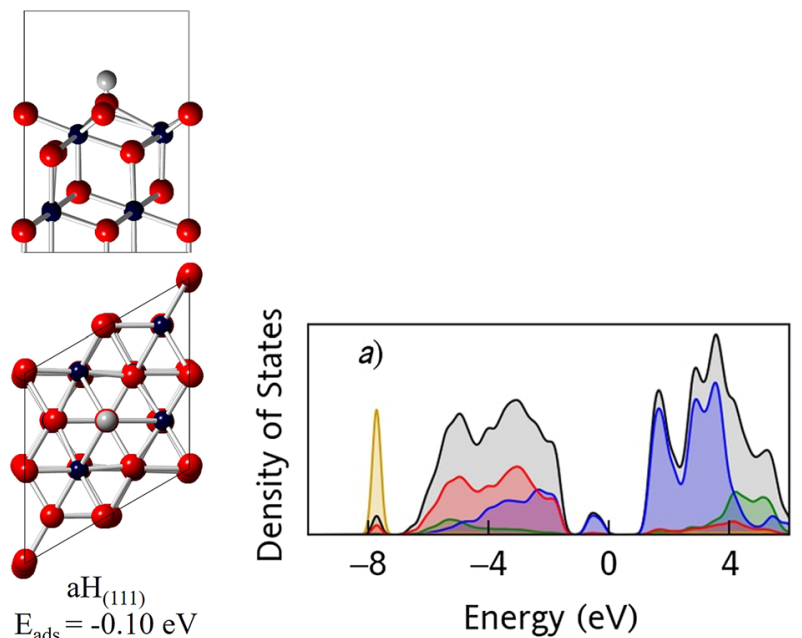

FIG. 5. The adsorption sites of atomic $\mathrm{H}$ on the $\mathrm{NpO}_{2}$ (111) surface. The $\mathrm{Np}^{4+}$ (blue), $\mathrm{O}^{2-}$ (red), and $\mathrm{H}$ (grey) ions are indicated. The energy of adsorption $\left(\mathrm{E}_{\mathrm{ads}}\right)$ is also shown. The density of states of the $\mathrm{aH}_{(111)}$ configuration for the $\mathrm{NpO}_{2}(111)$ surface has been calculated. The total density of states (black), Np f- (blue), Np d(green), O p- (red), and H s- (yellow) bands are coloured. Note that the hydrogen $\mathrm{s}$-band has been magnified by a factor of 40 for clarity. 

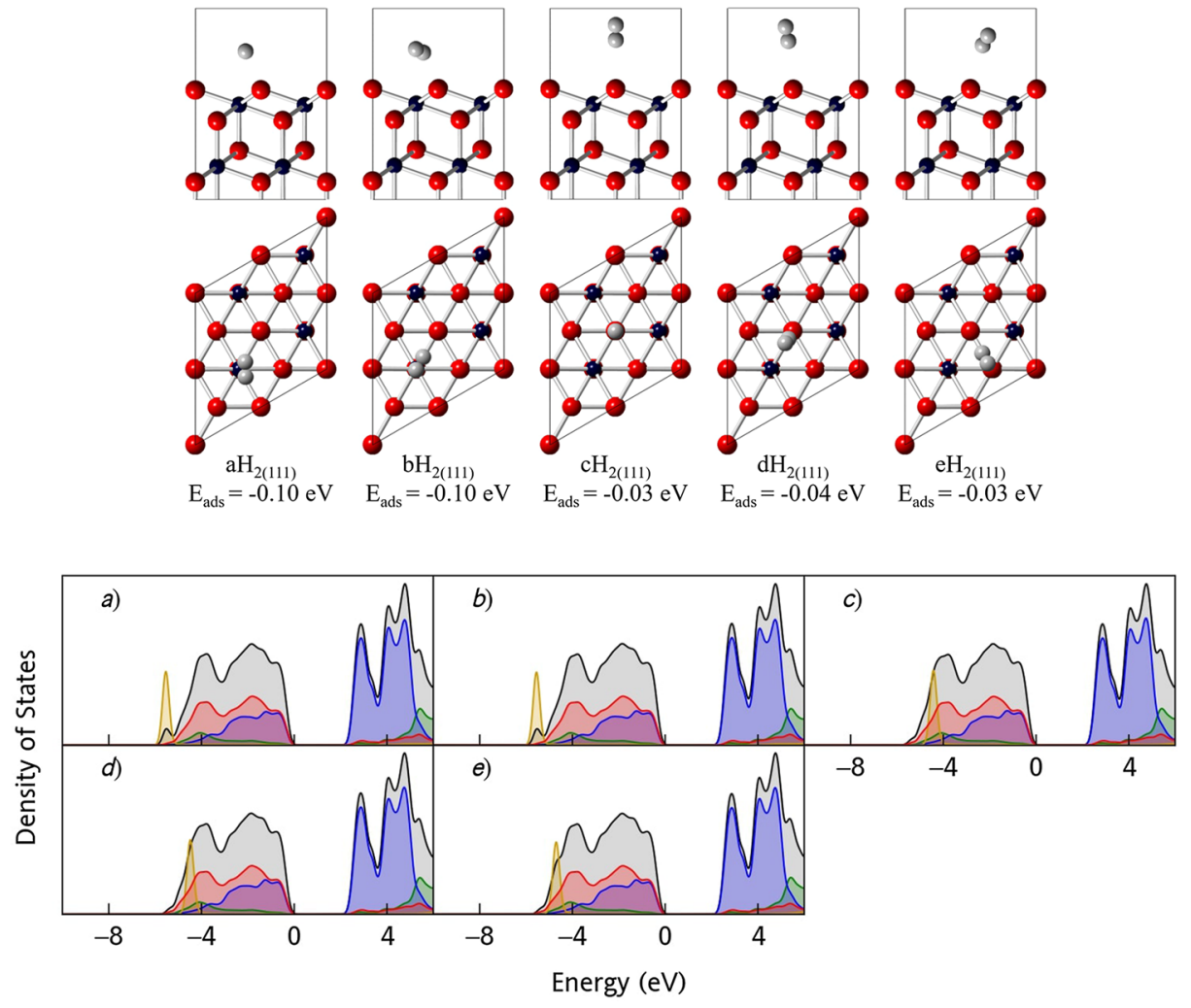

FIG. 6. The adsorption sites of molecular $\mathrm{H}_{2}$ on the $\mathrm{NpO}_{2}$ (111) surface. The $\mathrm{Np}^{4+}$ (blue), $\mathrm{O}^{2-}$ (red), and $\mathrm{H}$ (grey) ions are indicated. The energy of adsorption ( $\left.E_{\text {ads }}\right)$ is also shown. The density of states of the a-e $\mathrm{H}_{2(111)}$ configurations for the $\mathrm{NpO}_{2}$ (111) surface has been calculated. The total density of states (black), Np f- (blue), Np d- (green), O p- (red), and $\mathrm{H} \mathrm{s}$ - (yellow) bands are coloured. Note that the hydrogen s-band has been magnified by a factor of 10 for clarity. above the $\mathrm{Np}$ ion. As the adoption energetics of atomic $\mathrm{H}$ and molecular $\mathrm{H}_{2}$ are comparable, the dissociation of molecular $\mathrm{H}_{2}$ is less favoured on the $\mathrm{NpO}_{2}$ (111) surface.

By analysis of the Bader charge distribution of the atomic $\mathrm{aH}_{(111)}$ state, a limitation of the (1-1) unit cell model employed is the inability to partition the electron density over a larger surface area. In addition, a large energetic barrier, introduced from the need to spread the negative charge over a greater distance, possibly hinders the formation of two $\mathrm{OH}$ groups. As such, even if molecular $\mathrm{H}_{2}$ dissociates, recombination is highly probable. Given the surface areas involved in the distribution of charges, kinetic factors likely control the dissociation of molecular $\mathrm{H}_{2}$ on the $\mathrm{NpO}_{2}$ (111) surface. The dissociation mechanism may proceed by elongation of the $\mathrm{H}-\mathrm{H}$ bond as each $\mathrm{H}$ ion moves towards an $\mathrm{O}_{(\mathrm{S})}$ ion, or by the formation of a $\mathrm{NpH}$ and $\mathrm{OH}$ pair, with these mechanisms being analogues with those proposed for $\mathrm{UO}_{2}$.

\section{Plutonium dioxide}

The interaction of hydrogen with the $\mathrm{PuO}_{2}$ (111) surface results in $\mathrm{a}-\mathrm{bH}_{(111)}$ configurations (Fig. 7). The $\mathrm{aH}_{(111)}$ configuration is characterised by an endothermic adsorption energy of $2.18 \mathrm{eV}$, whereas the $\mathrm{bH}_{(111)}$ configuration is characterised by an exothermic adsorption energy of $-1.25 \mathrm{eV}$. In the $\mathrm{aH}_{(111)}$ configuration, the atomic $\mathrm{H}$ is positioned directly above a $\mathrm{Pu}$ ion. After a full ionic relaxation of hydrogen and the surface ions, the minimum $\mathrm{Pu}-\mathrm{H}(2.403 \AA)$ and $\mathrm{O}-\mathrm{H}(2.754 \AA)$ distances have been calculated. The configuration shares structural similarities with the $\mathrm{UO}_{2}$
$\mathrm{aH}_{(111)}$ configuration, although the endothermic energy of adsorption is considerably greater. In reference to the $\mathrm{UO}_{2} \mathrm{bH}_{(111)}$ site and the $\mathrm{NpO}_{2} \mathrm{aH}_{(111)}$ configurations, the $\mathrm{PuO}_{2} \mathrm{bH}_{(111)}$ configuration is almost identical in terms of structural configuration. The energy of absorption decreases from $0.82 \mathrm{eV}$ to $-1.25 \mathrm{eV}$ along the $\mathrm{AnO}_{2}$
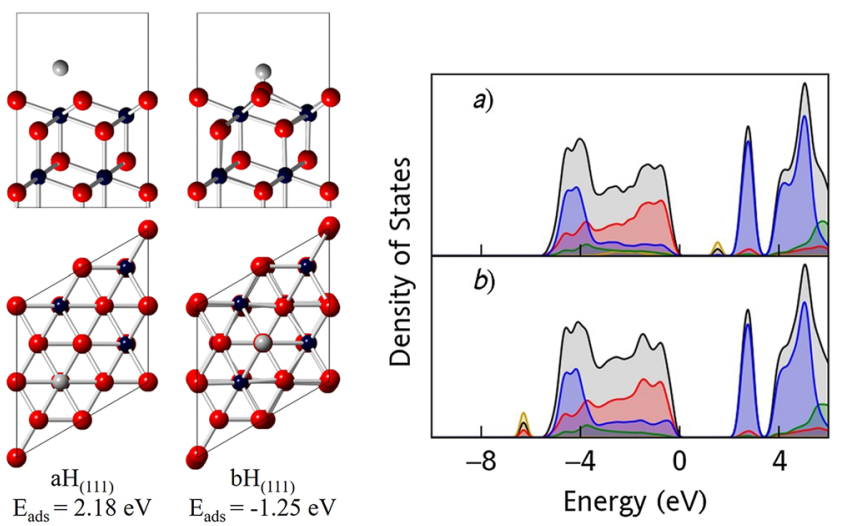

FIG. 7. The adsorption sites of atomic $\mathrm{H}$ on the $\mathrm{PuO}_{2}$ (111) surface. The $\mathrm{Pu}^{4+}$ (blue), $\mathrm{O}^{2-}$ (red), and $\mathrm{H}$ (grey) ions are indicated. The energy of adsorption ( $\left.\mathrm{E}_{\mathrm{ads}}\right)$ is also shown. The density of states of the a-bH $\mathrm{H}_{(111)}$ configurations for the $\mathrm{PuO}_{2}$ (111) surface has been calculated. The total density of states (black), Pu f- (blue), Pu d- (green), $\mathrm{O}$ p- (red), and $\mathrm{H}$ s- (yellow) bands are coloured. Note that the hydrogen s-band has been magnified by a factor of 40 for clarity. 
$(\mathrm{An}=\mathrm{U}, \mathrm{Np}$, and $\mathrm{Pu})$ series, which offers an indication of the increasing reactivity of the $\mathrm{AnO}_{2}$ (111) surfaces. In the $\mathrm{bH}_{(111)}$ site, the $\mathrm{H}$ atom is bonded to an $\mathrm{O}_{(\mathrm{S})}$ atom to form an $\mathrm{OH}$ group, where the $\mathrm{O}-\mathrm{H}$ bond distance of $0.976 \AA$ is consistent with that of an $\mathrm{OH}$ group. The adsorption energy of $-1.25 \mathrm{eV}$ indicates an exothermic chemisorption mechanism. At the $\mathrm{O}_{(\mathrm{S})}$ site, the neighbouring oxygen ions are drawn inwards, which results in a slight structural deformation. The formation of the $\mathrm{OH}$ group is confirmed by the $\mathrm{H}$ ion Bader charge of $0.58 \mathrm{eV}$ (Table A3). This indicates a protonic state. In addition, the $\mathrm{Pu}(\mathrm{d})$ ion is reduced, whereas the $\mathrm{O}$ ions are only partially oxidised. In each instance, the electronic structure of the $\mathrm{PuO}_{2}$ (111) surface is relatively unaffected and indicates molecular $\mathrm{H}_{2}$ physisorption. As there is clear evidence of atomic $\mathrm{H}$ chemisorption on the $\mathrm{PuO}_{2}$ (111) surface, it is perhaps surprising that the dissociation of molecular $\mathrm{H}_{2}$ is not observed. As the charge cannot be distributed over a larger surface area, the $\mathrm{aH}_{(111)}$ result implies a limitation of a (1·1) unit cell model. A large energetic barrier is thought to inhibit a dissociative adsorption mechanism, although cNEB calculations would markedly confirm the idea.

The instability of the $\mathrm{aH}_{(111)}$ configuration is highlighted by the $\mathrm{H}$ s-defect state located within the bandgap. In the $\mathrm{bH}_{(111)}$ configuration, the number of $\mathrm{Pu}$-states in the valence band has increased, whereas the number of Pu f-states in the conduction band has decreased. These changes indicate that high-energy Pu f-states (due to the interaction of hydrogen) are shifted to lower energy levels. The reduction of the formal $\mathrm{Pu}^{4+}(2.47 \mathrm{eV})$ ion to $\mathrm{Pu}^{3+}(2.08 \mathrm{eV})$ ion by hydrogen is confirmed by the Bader charge. Additionally, the hybridisation of the $\mathrm{H} \mathrm{s}$ - and $\mathrm{O}$ p-states at $6 \mathrm{eV}$ is indicative of the formation of an $\mathrm{OH}$ group.

In comparison, the interaction of molecular $\mathrm{H}_{2}$ on the $\mathrm{PuO}_{2}$ (111) surface results in four distinct a- $\mathrm{dH}_{2(111)}$ configurations (Fig. 8). As with the $\mathrm{UO}_{2}$ (111) and $\mathrm{NpO}_{2}$ (111) surfaces, the dissociation of the molecular $\mathrm{H}_{2}$ on the $\mathrm{PuO}_{2}$ (111) surface is not observed. In each instance, the physisorption of molecular $\mathrm{H}_{2}$ is in an energy range of $-0.01 \mathrm{eV}$ to $-0.09 \mathrm{eV}$. The $\mathrm{aH}_{2(111)}$ site, relative to the $\mathrm{bH}_{2(111)}$ site, is marginally higher in energy by $0.01 \mathrm{eV}$. In both instances, molecular $\mathrm{H}_{2}$ is positioned proximal to a $\mathrm{Pu}$ ion. In the $\mathrm{cH}_{2(111)}$ site, molecular $\mathrm{H}_{2}$ is located above an $\mathrm{O}_{(\mathrm{S})}$ ion with an adsorption energy of $-0.03 \mathrm{eV}$. The configuration potentially acts as an intermediate position for the dissociation of $\mathrm{H}_{2}$ and the formation of an $\mathrm{OH}$ group. This is seen in the atomic $\mathrm{aH}_{(111)}$ site; however, as stated, this has not been observed in these calculations. In addition, the $\mathrm{dH}_{2(111)}$ site is reminiscent of the $\mathrm{cH}_{2(111)}$

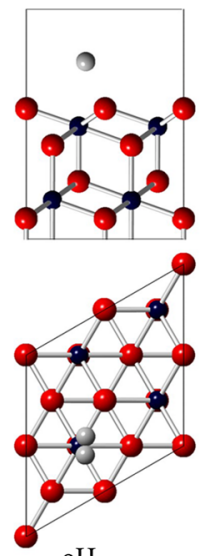

$\mathrm{aH}_{2(111)}$ $\mathrm{E}_{\mathrm{ads}}=-0.08 \mathrm{eV}$
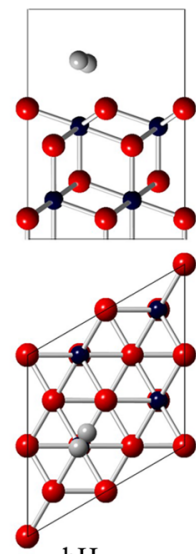

$\mathrm{bH}_{2(111)}$ $\mathrm{E}_{\mathrm{ads}}=-0.09 \mathrm{eV}$

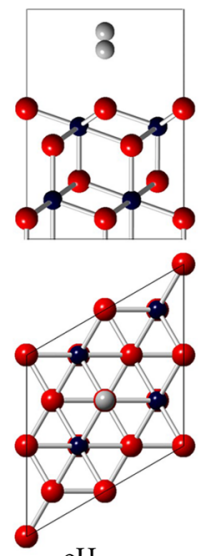

$\mathrm{cH}_{2(111)}$ $\mathrm{E}_{\mathrm{ads}}=-0.03 \mathrm{eV}$

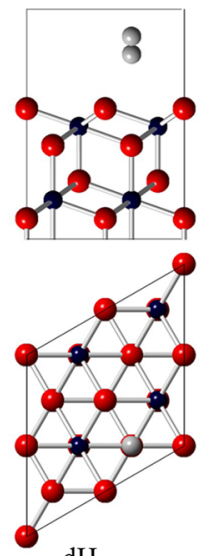

$\mathrm{dH}_{2(111)}$ $\mathrm{E}_{\mathrm{ads}}=-0.01 \mathrm{eV}$

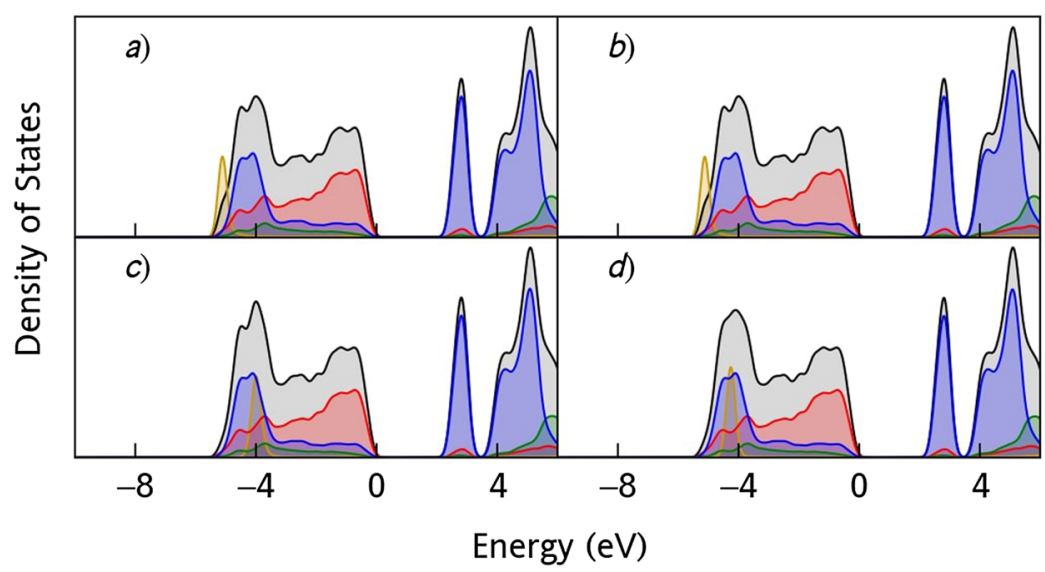

FIG. 8. The adsorption sites of molecular $\mathrm{H}_{2}$ on the $\mathrm{PuO}_{2}$ (111) surface. The $\mathrm{Pu}^{4+}$ (blue), $\mathrm{O}^{2-}$ (red), and $\mathrm{H}$ (grey) ions are indicated. The energy of adsorption $\left(E_{a d s}\right)$ is also shown. The density of states of the a- $\mathrm{dH}_{2(111)}$ configurations for the $\mathrm{PuO}_{2}$ (111) surface has been calculated. The total density of states (black), Pu f- (blue), Pu d- (green), O p(red), and $\mathrm{H} \mathrm{s}$ - (yellow) bands are coloured. Note that the hydrogen s-band has been magnified by a factor of 10 for clarity. 
site, although molecular $\mathrm{H}_{2}$ is now located above the $\mathrm{O}_{(\mathrm{I})}$ ion. The lowest-energy $\mathrm{bH}_{2(111)}$ site is characterised by an adsorption energy of $-0.09 \mathrm{eV}$. A physisorption mechanism is confirmed by the Bader charge distribution (Table A3). The disruption to the surface is negligible, and the hydrogen ions remain effectively charge neutral.

In each instance, the electronic structure of the $\mathrm{PuO}_{2}$ (111) surface is relatively unaffected, which indicates molecular $\mathrm{H}_{2}$ physisorption. As there is clear evidence of atomic $\mathrm{H}$ chemisorption on the $\mathrm{PuO}_{2}$ (111) surface, it is perhaps surprising that the dissociation of molecular $\mathrm{H}_{2}$ is not observed. A large energetic barrier is thought to influence the adsorption mechanism, which in future could be confirmed by cNEB calculations and the use of a (2.2) unit cell. This offers the option of distributing the charge imparted by the adsorption of a $\mathrm{H}$ ion over a larger surface area.

\section{CONCLUSIONS}

The interactions of atomic $\mathrm{H}$ and molecular $\mathrm{H}_{2}$ on the $\mathrm{AnO}_{2}$ $(\mathrm{An}=\mathrm{U}, \mathrm{Np}, \mathrm{Pu})(111)$ surfaces has been investigated by $\mathrm{DFT}+\mathrm{U}$. The study considers SOI and noncollinear 3k AFM behaviour. The reactivity of the $\mathrm{AnO}_{2}$ (111) surfaces increase along the $\mathrm{U}-\mathrm{Pu}$ series. Multiple adsorption configurations were identified on the $\mathrm{UO}_{2}$ and $\mathrm{PuO}_{2}$ surfaces, while only one was found on $\mathrm{NpO}_{2}$. In the interaction of atomic $\mathrm{H}$ with the $\mathrm{AnO}_{2}$ (111) surfaces, an $\mathrm{OH}$ group is formed coupled with the reduction of an An ion. The energy of atomic $\mathrm{H}$ adsorption for $\mathrm{UO}_{2}(0.82 \mathrm{eV})$, $\mathrm{NpO}_{2}(-0.10 \mathrm{eV})$, and $\mathrm{PuO}_{2}(-1.25 \mathrm{eV})$ is shown and is caused by increasing surface instability along the actinide series. ${ }^{6}$ A clear shift from an endothermic to an exothermic mechanism is identified. The formation of the $\mathrm{OH}$ group is confirmed by the DoS and the Bader charge distribution. The structure of the low-energy $\mathrm{UO}_{2}$ $\mathrm{bH}_{(111)}, \mathrm{NpO}_{2} \mathrm{aH}_{(111)}$, and $\mathrm{PuO}_{2} \mathrm{bH}_{(111)}$ configurations is effectively identical.

The dissociation of molecular $\mathrm{H}_{2}$ on the $\mathrm{AnO}_{2}$ (111) surface is not observed; instead, molecular $\mathrm{H}_{2}$ is weakly physisorbed. As the formation of the $\mathrm{OH}$ group is thermodynamically feasible, the dissociation of molecular $\mathrm{H}_{2}$ is possibly hindered by kinetic factors. These observations can be explained in terms of the charge distribution, where the furthest actinide ion from the adsorption site is reduced. The inability to distribute charge is a key limitation of a $(1 \cdot 1)$ unit cell model, which is thought to hinder the formation of a second $\mathrm{OH}$ group. To incorporate the reduction of another An ion furthest away from the $\mathrm{OH}$ group, a second unit cell must be included within the model. Although a fully relativistic cNEB investigation is computationally intractable at this time, future investigations should consider the reaction pathways proposed in this study. The diffusion of hydrogen through the $\mathrm{AnO}_{2}$ can be investigated by molecular dynamics. Investigation of hydrogen interactions with $\mathrm{AnO}_{2}$ (011) and (001) surfaces for comparison are also planned. ${ }^{6}$

\section{SUPPLEMENTARY MATERIAL}

See supplementary material for the following information: Clean surface-fixed unit cell dimensions, ionic positions, magnetic structure, k-point convergence, and electronic density of states, and hydrogen interactions-ionic positions, magnetic structure, and Bader charges.

\section{ACKNOWLEDGMENTS}

This research was supported by the UK Engineering and Physical Science Research Council (EPSRC) (Grant Nos. EP/G036675 and EP/K016288) and the Atomic Weapons Establishment (AWE). A.E.S. gratefully acknowledges the United States Department of Homeland Security (DHS), Domestic Nuclear Detection Office (DNDO), National Technical Nuclear Forensics Centre (NTNFC) for a Postdoctoral Research Fellowship. N.H.d.L. thanks the Royal Society for an Industry Fellowship and AWE for a William Penney Fellowship. This work made use of the ARCHER UK National Supercomputing Service (http://www.archer.ac.uk), via our membership of the UK's HEC Materials Chemistry Consortium, which is funded by EPSRC (Grant No. EP/L000202).

\section{REFERENCES}

${ }^{1}$ J. J. Katz, The Chemistry of the Actinide and Transactinide Elements (Springer Science and Business Media, 2007), Vols. 1-5.

${ }^{2}$ V. V. Rondinella and T. Wiss, "The high burn-up structure in nuclear fuel," Mater Today 13(12), 24-32 (2010).

${ }^{3}$ M. Stan, "Discovery and design of nuclear fuels," Mater Today 12(11), 20-28 (2009).

${ }^{4}$ J. R. Gregory, M. Astill, and M. G. Waine, "Reprocessing nuclear fuel," GB patent document 2031217/A/ (16 April 1980), available at http://inis.iaea.org/search/ search.aspx?orig_q=RN:11564664.

${ }^{\mathbf{5}}$ H. E. Sims, K. J. Webb, J. Brown, D. Morris, and R. J. Taylor, "Hydrogen yields from water on the surface of plutonium dioxide," J. Nucl. Mater. 437(1), 359-364 (2013).

${ }^{6}$ J. T. Pegg, "A noncollinear relativistic computational study of the actinide dioxides and their interaction with hydrogen," Engineering Doctorate, University College London, UCL, 2018.

${ }^{7}$ J. M. Haschke, T. H. Allen, and J. C. Martz, "Oxidation kinetics of plutonium in air: Consequences for environmental dispersal,” J. Alloys Compd. 271-273, 211-215 (1998).

${ }^{8}$ J. M. Haschke, T. H. Allen, and J. L. Stakebake, "Reaction kinetics of plutonium with oxygen, water and humid air: Moisture enhancement of the corrosion rate," J. Alloys Compd. 243(1-2), 23-35 (1996).

${ }^{9}$ J. M. Haschke, T. H. Allen, and L. A. Morales, "Reactions of plutonium dioxide with water and hydrogen-oxygen mixtures: Mechanisms for corrosion of uranium and plutonium," J. Alloys Compd. 314(1-2), 78-91 (2001).

${ }^{10}$ R. C. Ewing, "Long-term storage of spent nuclear fuel," Nat. Mater. 14(3), 252-257 (2015).

${ }^{11}$ J. M. Haschke, T. H. Allen, and L. A. Morales, "Surface and corrosion chemistry of plutonium," Los Alamos Sci. 26(2), 252-273 (2000).

${ }^{12}$ L. Venault, A. Deroche, J. Gaillard, O. Lemaire, N. Budanova, J. Vermeulen et al., "Dihydrogen $\mathrm{H}_{2}$ steady state in $\alpha$-radiolysis of water adsorbed on $\mathrm{PuO}_{2}$ surface," Radiat. Phys. Chem. (published online).

${ }^{13}$ J. M. Haschke, "Corrosion of uranium in air and water vapor: Consequences for environmental dispersal,” J. Alloys Compd. 278(1-2), 149-160 (1998).

${ }^{14}$ J. M. Haschke, T. H. Allen, and L. A. Morales, "Reaction of plutonium dioxide with water: Formation and properties of $\mathrm{PuO}_{2+\mathrm{x}}$," Science 287(5451), 285-287 (2000).

${ }^{15}$ A. E. Shields, A Computational Analysis of Thorium Dioxide and $\mathrm{Th}_{(1-x)} \mathrm{U}_{x} \mathrm{O}_{2}$ Systems (University College London, UCL, 2015).

${ }^{16}$ A. E. Shields, D. Santos-Carballal, and N. H. de Leeuw, "A density functional theory study of uranium-doped thoria and uranium adatoms on the major surfaces of thorium dioxide," J. Nucl. Mater. 473, 99-111 (2016).

${ }^{17}$ A. E. Shields, A. J. Miskowiec, J. L. Niedziela, M. C. Kirkegaard, K. Maheshwari, M. W. Ambrogio et al., "Shining a light on amorphous $\mathrm{U}_{2} \mathrm{O}_{7}$ : A computational approach to understanding amorphous uranium materials," Opt. Mater. 89, 295-298 (2019). 
${ }^{18}$ T. Bo, J.-H. Lan, C.-Z. Wang, Y.-L. Zhao, C.-H. He, Y.-J. Zhang et al., "First-principles study of water reaction and $\mathrm{H}_{2}$ formation on $\mathrm{UO}_{2}$ (111) and (110) single crystal surfaces," J. Phys. Chem. C 118(38), 21935-21944 (2014).

${ }^{19}$ T. Bo, J.-H. Lan, Y.-L. Zhao, Y.-J. Zhang, C.-H. He, Z.-F. Chai et al., "Surface properties of $\mathrm{NpO}_{2}$ and water reacting with stoichiometric and reduced $\mathrm{NpO}_{2}$ (111), (110), and (100) surfaces from ab initio atomistic thermodynamics," Surf. Sci. 644, 153-164 (2016).

${ }^{20}$ T. Bo, J.-H. Lan, Y.-L. Zhao, Y.-J. Zhang, C.-H. He, Z.-F. Chai et al., "Firstprinciples study of water adsorption and dissociation on the $\mathrm{UO}_{2}(111),(110)$ and (100) surfaces," J. Nucl. Mater. 454(1), 446-454 (2014).

${ }^{21} \mathrm{~J}$. M. Haschke and T. H. Allen, "Plutonium hydride, sesquioxide and monoxide monohydride: Pyrophoricity and catalysis of plutonium corrosion," J. Alloys Compd. 320(1), 58-71 (2001).

${ }^{22}$ J. M. Haschke and J. C. Martz, "Catalyzed corrosion of plutonium: Hazards and applications," Los Alamos Sci. 26, 266-267 (2000).

${ }^{23} \mathrm{~B}$. Ao, R. Qiu, H. Lu, and P. Chen, "Differences in the existence states of hydrogen in $\mathrm{UO}_{2}$ and $\mathrm{PuO}_{2}$ from DFT+U calculations," J. Phys. Chem. C 120(33), 18445-18451 (2016)

${ }^{24}$ B. Ao, R. Qiu, G. Zhang, Z. Pu, X. Wang, and P. Shi, "Light impurity atoms as the probes for the electronic structures of actinide dioxides," Comput. Mater. Sci. 142, 25-31 (2018).

${ }^{25}$ B. E. Tegner, M. Molinari, A. Kerridge, S. C. Parker, and N. Kaltsoyannis, "Water adsorption on $\mathrm{AnO}_{2}\{111\},\{110\}$, and $\{100\}$ surfaces $(\mathrm{An}=\mathrm{U}$ and $\mathrm{Pu})$ : $\mathrm{A}$ density functional theory+U study," J. Phys. Chem. C 121(3), 1675-1682 (2017).

${ }^{26}$ J. M. Flitcroft, M. Molinari, N. A. Brincat, M. T. Storr, and S. C. Parker, "Hydride ion formation in stoichiometric $\mathrm{UO}_{2}$," Chem. Commun. 51(90), 16209-16212 (2015).

${ }^{27}$ M. Flitcroft Joseph, M. Molinari, N. A. Brincat, N. R. Williams, M. T. Storr, G. C. Allen et al., "The critical role of hydrogen on the stability of oxyhydroxyl defect clusters in uranium oxide," J. Mater Chem. A 6(24), 11362-11369 (2018).

${ }^{28} \mathrm{~J}$. Glascott, "A model for the initiation of reaction sites during the uraniumhydrogen reaction assuming enhanced hydrogen transport through linear oxide discontinuities," Philos. Mag. 94(13), 1393-1413 (2014).

${ }^{29} \mathrm{~J}$. Glascott, "A model for the initiation of reaction sites during the uraniumhydrogen reaction assuming enhanced hydrogen transport through thin areas of surface oxide," Philos. Mag. 94(3), 221-241 (2014).

${ }^{30}$ N. A. Brincat, M. Molinari, S. C. Parker, G. C. Allen, and M. T. Storr, "Computer simulation of defect clusters in $\mathrm{UO}_{2}$ and their dependence on composition," J. Nucl. Mater. 456, 329-333 (2015).

${ }^{31}$ M. Fronzi, S. Piccinin, B. Delley, E. Traversa, and C. Stampfl, "Water adsorption on the stoichiometric and reduced $\mathrm{CeO}_{2}(111)$ surface: A first-principles investigation," Phys. Chem. Chem. Phys. 11(40), 9188-9199 (2009).

${ }^{32}$ J. M. Haschke, H. K. Fauske, and A. G. Phillips, "Pyrophoric potential of plutonium-containing salt residues," J. Nucl. Mater. 279(2-3), 127-138 (2000).

${ }^{33}$ J. T. Pegg, A. E. Shields, M. T. Storr, D. O. Scanlon, and N. H. de Leeuw, "Noncollinear relativistic DFT $+\mathrm{U}$ calculations of actinide dioxide surfaces," J. Phys. Chem. C 123(1), 356-366 (2019).

${ }^{34}$ J. T. Pegg, A. E. Shields, M. T. Storr, A. S. Wills, D. O. Scanlon, and N. H. de Leeuw, "Hidden magnetic order in plutonium dioxide nuclear fuel," Phys. Chem. Chem. Phys. 20(32), 20943-20951 (2018).

${ }^{35} \mathrm{~J}$. T. Pegg, A. E. Shields, M. T. Storr, A. S. Wills, D. O. Scanlon, and N. H. de Leeuw, "Magnetic structure of $\mathrm{UO}_{2}$ and $\mathrm{NpO}_{2}$ by first-principle methods," Phys. Chem. Chem. Phys. 21(2), 760-771 (2019).

${ }^{36}$ J. P. Perdew and A. Zunger, "Self-interaction correction to density-functional approximations for many-electron systems," Phys. Rev. B 23(10), 5048-5079 (1981).

${ }^{37}$ P. Hohenberg and W. Kohn, "Inhomogeneous electron gas," Phys. Rev. 136(3B), B864-B71 (1964).

${ }^{38}$ W. Kohn and L. J. Sham, "Self-consistent equations including exchange and correlation effects," Phys. Rev. 140(4A), A1133-A1138 (1965).

${ }^{39}$ S. L. Dudarev, G. A. Botton, S. Y. Savrasov, C. J. Humphreys, and A. P. Sutton, "Electron-energy-loss spectra and the structural stability of nickel oxide: An LSDA+U study," Phys. Rev. B 57(3), 1505-1509 (1998).
${ }^{40}$ A. I. Liechtenstein, V. I. Anisimov, and J. Zaanen, "Density-functional theory and strong interactions: Orbital ordering in Mott-Hubbard insulators," Phys. Rev. B 52(8), R5467-R5470 (1995).

${ }^{41}$ V. I. Anisimov, J. Zaanen, and O. K. Andersen, "Band theory and Mott insulators: Hubbard U instead of stoner I," Phys. Rev. B 44(3), 943-954 (1991).

${ }^{42} \mathrm{C}$. Adamo and V. Barone, "Toward reliable density functional methods without adjustable parameters: The PBE0 model," J. Chem. Phys. 110(13), 6158-6170 (1999).

${ }^{43}$ J. Heyd, G. E. Scuseria, and M. Ernzerhof, "Hybrid functionals based on a screened Coulomb potential," J. Chem. Phys. 118(18), 8207-8215 (2003).

${ }^{44}$ I. D. Prodan, G. E. Scuseria, and R. L. Martin, "Covalency in the actinide dioxides: Systematic study of the electronic properties using screened hybrid density functional theory," Phys. Rev. B 76(3), 033101 (2007).

${ }^{45}$ A. Georges, G. Kotliar, W. Krauth, and M. J. Rozenberg, "Dynamical meanfield theory of strongly correlated fermion systems and the limit of infinite dimensions," Rev. Mod. Phys. 68(1), 13 (1996).

${ }^{46} \mathrm{P}$. W. Anderson, "Antiferromagnetism. Theory of superexchange interaction," Phys. Rev. 79(2), 350-356 (1950).

${ }^{47}$ R. Caciuffo, N. Magnani, P. Santini, S. Carretta, G. Amoretti, E. Blackburn et al., "Anisotropic magnetic fluctuations in 3-k antiferromagnets," J. Magn. Magn. Mater. 310(2, Part 2), 1698-1702 (2007).

${ }^{48} \mathrm{P}$. Giannozzi and P. Erdös, "Theoretical analysis of the 3-k magnetic structure and distortion of uranium dioxide," J. Magn. Magn. Mater. 67(1), 75-87 (1987).

${ }^{49}$ W. Kopmann, F. J. Litterst, H. H. Klauß, M. Hillberg, W. Wagener, G. M. Kalvius et al., "Magnetic order in $\mathrm{NpO}_{2}$ and $\mathrm{UO}_{2}$ studied by muon spin rotation," J. Alloys Compd. 271-273, 463-466 (1998).

${ }^{50}$ D. Mannix, G. H. Lander, J. Rebizant, R. Caciuffo, N. Bernhoeft, E. Lidström et al., "Unusual magnetism of $\mathrm{NpO}_{2}$ : A study with resonant X-ray scattering," Phys. Rev. B 60(22), 15187-15193 (1999).

${ }^{51}$ P. Santini, R. Lémanski, and P. Erdős, "Magnetism of actinide compounds," Adv. Phys. 48(5), 537-653 (1999).

${ }^{52}$ J. T. Pegg, X. Aparicio-Anglès, M. Storr, and N. H. de Leeuw, "DFT+U study of the structures and properties of the actinide dioxides," J. Nucl. Mater. 492, 269-278 (2017).

${ }^{53}$ G. van der Laan, K. T. Moore, J. G. Tobin, B. W. Chung, M. A. Wall, and A. J. Schwartz, "Applicability of the spin-orbit sum rule for the actinide $5 \mathrm{f}$ states," Phys. Rev. Lett. 93(9), 097401 (2004).

${ }^{54}$ Z. Rák, R. C. Ewing, and U. Becker, "Hydroxylation-induced surface stability of $\mathrm{AnO}_{2}(\mathrm{An}=\mathrm{U}, \mathrm{Np}, \mathrm{Pu})$ from first-principles," Surf. Sci. 608, 180-187 (2013).

${ }^{55}$ S. A. Moten, R. Atta-Fynn, A. K. Ray, and M. N. Huda, "Size effects on the electronic and magnetic properties of $\mathrm{PuO}_{2}$ (111) surface," J. Nucl. Mater. 468, $37-45$ (2016).

${ }^{56} \mathrm{~J}$. Boettger and A. Ray, "Fully relativistic density functional calculations on hydroxylated actinide oxide surfaces," Int. J. Quantum Chem. 90(4-5), 1470-1477 (2002).

${ }^{57}$ V. I. Anisimov, Strong Coulomb Correlations in Electronic Structure Calculations (CRC Press, 2000).

${ }^{58}$ J. Heyd, G. E. Scuseria, and M. Ernzerhof, "Erratum: 'Hybrid functionals based on a screened Coulomb potential' [J. Chem. Phys. 118, 8207 (2003)]," J. Chem. Phys. 124(21), 219906 (2006).

${ }^{59}$ P. E. Blöchl, O. Jepsen, and O. K. Andersen, "Improved tetrahedron method for Brillouin-zone integrations,” Phys. Rev. B 49(23), 16223 (1994).

${ }^{60}$ G. I. Csonka, J. P. Perdew, A. Ruzsinszky, P. H. Philipsen, S. Lebègue, J. Paier et al., "Assessing the performance of recent density functionals for bulk solids," Phys. Rev. B 79(15), 155107 (2009).

${ }^{61}$ G. W. Watson, E. T. Kelsey, N. H. de Leeuw, D. J. Harris, and S. C. Parker, "Atomistic simulation of dislocations, surfaces and interfaces in $\mathrm{MgO}$," J. Chem. Soc., Faraday Trans. 92(3), 433-438 (1996).

${ }^{62} \mathrm{~W}$. Sun and G. Ceder, "Efficient creation and convergence of surface slabs," Surf. Sci. 617, 53-59 (2013).

${ }^{63}$ R. C. Weast, M. J. Astle, and W. H. Beyer, CRC Handbook of Chemistry and Physics (CRC Press, Boca Raton, FL, 1988).

${ }^{64}$ A. Balakrishnan, V. Smith, and B. P. Stoicheff, "Dissociation energy of the hydrogen molecule," Phys. Rev. Lett. 68(14), 2149-2152 (1992). 
${ }^{65}$ G. Herzberg, "The dissociation energy of the hydrogen molecule," J. Mol. Spectrosc. 33(1), 147-168 (1970).

${ }^{66}$ J. H. De Boer, "50 endothermic chemisorption and catalysis," in Advances in Catalysis, edited by A. Farkas (Academic Press, 1957), Vol. 9, pp. 472-480.

${ }^{67}$ T. M. McCleskey, E. Bauer, Q. Jia, A. K. Burrell, B. L. Scott, S. D. Conradson et al., "Optical band gap of $\mathrm{NpO}_{2}$ and $\mathrm{PuO}_{2}$ from optical absorbance of epitaxial films,” J. Appl. Phys. 113(1), 013515 (2013).
${ }^{68}$ P. Erdös, G. Solt, Z. $\odot$ ołnierek, A. Blaise, and J. M. Fournier, "Magnetic susceptibility and the phase transition of $\mathrm{NpO}_{2}$," Physica $\mathrm{B}+\mathrm{C}$. 102(1), 164-170 (1980).

${ }^{69}$ C. Suzuki, T. Nishi, M. Nakada, M. Akabori, M. Hirata, and Y. Kaji, "Core-hole effect on XANES and electronic structure of minor actinide dioxides with fluorite structure," J. Phys. Chem. Solids 73(2), 209-216 (2012). 